\title{
REDUÇÃO FECHADA E FIXAÇÃO ESQUELÉTICA EXTERNA TIPO II PARA O TRATÁMENTO DE FRATURAS DE TIBIOTARSO EM POMBOS DOMÉSTICOS

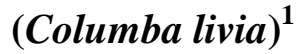

\section{CLOSED REDUCTION AND TYPE-II EXTERNAL SKELETAL FIXATION FOR TREATMENT OF TIBIOTARSUS FRACTURES IN DOMESTIC PIGEONS (Columba livia)}

\author{
Marcelo Meller Alievi ${ }^{2}$ João Eduardo Schossler ${ }^{3}$ Ricardo Alexandre Hippler $^{4}$ \\ Aline de Souza Alves ${ }^{5}$ Luiz Carlos de Pellegrini ${ }^{6}$ Ingeborg Maria Langohr ${ }^{4}$
}

RESUMO

\begin{abstract}
A redução fechada e o fixador esquelético externo tipo II foram avaliados para o tratamento de fraturas de tibiotarso em pombos domésticos (Columba livia). Foram utilizadas doze aves adultas. Os pombos foram anestesiados com a associação de xilazina e cetamina e, em seguida, foi realizada fratura do tibiotarso direito através de pressão digital sobre a diáfise do membro. Quatro pinos de Kirschner, dois proximais e dois distais ao foco da fratura, foram inseridos através de ambas as corticais ósseas e, após redução fechada da fratura, conectados externamente por duas barras de acrílico autopolimerizável, uma na face lateral e outra na face medial do membro. Em cinco aves, foi observado radiograficamente desvio ósseo angular, porém, a função do membro não foi afetada. O tempo médio e o desvio padrão para a cicatrização óssea foram $24,8 \pm 4,89$ dias. Os resultados demonstram que a redução fechada e o fixador esquelético externo tipo II são efetivos para o tratamento de fraturas de tibiotarso em pombos domésticos (Columba livia).
\end{abstract}

Palavras-chave: aves, ortopedia, osteossíntese.

SUMMARY

The aim of this study was to evaluate the use of closed reduction and type-II external skeletal fixation for treatment of tibiotarsus fractures in domestic pigeons (Columba livia). Twelve adult domestic pigeons were used. Anesthesia was induced with xylazine and ketamine hydrochloride; the right

\begin{abstract}
tibiotarsus was manually fractured by digital pressure applied at the mid-diaphysis. Four Kirschner wires were placed through both cortices of the bone, two proximal and two distal to the fracture site, and, after closed reduction of the fracture, they were stabilized by two acrilic bars, one in the lateral and another in the medial surface of the tibiotarsus. Abnormalities in bone angulation were observed radiographically in five birds; however, the function of the limb was not noticeably impaired. The mean time \pm standard deviation for fracture healing was 24.8 \pm 4.89 days. The results of this experiment demonstrate that closed reduction and application of a type-II external skeletal fixation are effective for treatment of tibiotarsus fracture in domestic pigeons (Columba livia).
\end{abstract}

Key words: birds, orthopaedics, osteosynthesis.

\section{INTRODUÇÃO}

Segundo WILLIAMS et al. (1987) e MACCOY (1991), os objetivos do reparo das fraturas em aves são idênticos aos do reparo das fraturas em mamíferos. O primeiro é promover o correto alinhamento dos fragmentos ósseos, mantendo a biomecânica normal, e o segundo é proporcionar uma rígida estabilização da fratura. Tal estabilização promove rápida formação de calo ósseo, minimizando os danos às estruturas

${ }^{1}$ Parte da Dissertação de Mestrado em Medicina Veterinária apresentada pelo primeiro autor à Universidade Federal de Santa Maria (UFSM).

${ }^{2}$ Médico Veterinário, Mestre, Professor Substituto da Universidade Federal do Rio Grande do Sul. Faculdade de Veterinária, Av. Bento Gonçalves, n.9090, CP 15094, 91540-000, Bairro Agronomia, Porto Alegre, RS. E-mail: malievi@bol.com.br Autor para correspondência.

${ }^{3}$ Médico Veterinário, Professor Adjunto, Departamento de Clínica de Pequenos Animais, UFSM.

${ }^{4}$ Mestrando do programa de Pós-graduação em Medicina Veterinária, UFSM.

${ }^{5}$ Doutorando do programa de Pós-graduação em Medicina Veterinária, UFSM

${ }^{6}$ Médico Veterinário, Professor Adjunto, Departamento de Clínica de Grandes Animais, UFSM. 
adjacentes e inibindo o risco de lesões em nervos, vasos ou músculos pelos fragmentos ósseos instáveis. Assim, conforme BUSH (1977), permitirse-á, o uso do membro fraturado durante a reparação da fratura, diminuindo com isso o tempo de cicatrização.

Normalmente, os ossos das aves cicatrizam mais rapidamente que os dos mamíferos (NEWTON \& ZEITLIN, 1977; WISSMAN, 1999). Fraturas simples, fechadas e de diáfise do tibiotarso, quando adequadamente fixadas, podem tornar-se clinicamente estáveis em duas ou três semanas. Porém, o calo ósseo pode não ser visível radiograficamente nas três a seis semanas iniciais (BUSH et al., 1976; WISSMAN, 1999). WILLIAMS et al. (1987), provocando fratura e avaliando a cicatrização óssea em pombos, encontraram evidências de união periosteal após três semanas e completa união na sexta semana. TUDURY \& RAISER (1985), em cães, e WILLIAMS $\boldsymbol{e t} \boldsymbol{a l}$. (1987) e WISSMAN (1999), em pombos, verificaram que os sinais radiográficos de consolidação óssea acontecem mais tardiamente que os sinais clínicos.

Segundo BRADEN \& BRINKER (1973), a falta de uso do membro durante a fase de consolidação da fratura resulta na chamada "doença da fratura", que se caracteriza por atrofia muscular, rigidez articular, osteoporose e não-união óssea. Já o retorno precoce à utilização do membro fraturado reduz o tempo de internação hospitalar e permite o uso funcional do membro mais rapidamente.

Os aparelhos de fixação esquelética externa promovem bom alinhamento anatômico e adequada imobilização das extremidades fraturadas, resultando em rápida cicatrização, uso precoce do membro e mínima formação de calo ósseo (BUSH, 1977; SISK, 1983; WILLIAMS et al., 1987; PEAD \& CARMICHAEL, 1989; RAPHAEL et al., 1994). Embora esse método possa ser utilizado na maioria das aves, parece ser mais adequado para animais de médio e grande porte, com corticais ósseas espessas (BUSH, 1977; WESTFALL \& EGGER, 1979; WILLIAMS et al., 1987), pois nos animais de pequeno porte os ossos são menores e com corticais mais finas, dificultando assim a colocação do aparelho sem que ocorram fraturas ou fissuras (BELLANGEON \& PATAT, 1984). Segundo WILLIAMS $\boldsymbol{e t}$ al. (1987), os fixadores esqueléticos externos, especialmente os com duas barras de fixação (tipo II), promovem ótimo alinhamento anatômico e boa estabilização da fratura, com mínima perda funcional.

DEGERNES $\boldsymbol{e t}$ al. (1998), em um estudo utilizando úmeros e tibiotarsos de aves (Buteo jamaicensis), avaliando a capacidade de fixação de várias configurações de pinos, concluíram que os pinos lisos têm menor capacidade de se fixar no osso que os pinos com rosca e, por isso, não devem ser utilizados para a confecção de aparelhos de fixação esquelética externa. ROE (1995) indicou que, para a confecção de tais aparelhos, o diâmetro dos pinos não deve exceder a $30 \%$ do diâmetro ósseo. TOOMBS (1995), porém, citou que o diâmetro deve ser de aproximadamente $25 \%$, e HARARI $\boldsymbol{e t}$ al. (1998), por sua vez, citaram que o pino deve ter $20 \%$ do diâmetro ósseo. BRINKER et al. (1985) citam que a inserção dos pinos em ângulo reto em relação ao eixo longitudinal do osso aumenta a freqüência de afrouxamento dos pinos e, por isso, os pinos devem ter angulação de aproximadamente 70 graus, pois assim a chance de complicação é menor.

Segundo KUZMA (1992), um dos benefícios dos fixadores esqueléticos externos é a possibilidade de utilização da técnica fechada de redução óssea, ou seja, sem exposição dos fragmentos ósseos, o que não rompe o hematoma da fratura, mantém o suprimento sangüíneo e diminui os riscos de osteomielite. JOHNSON et al. (1989), em um estudo utilizando cães da rotina hospitalar, evidenciaram que nos animais em que foi realizada a redução fechada houve menor tempo para remoção do fixador e retorno mais rápido à utilização do membro fraturado. No mesmo estudo, identificaram um grande número de fraturas reduzidas com deformidades anatômicas, atribuindo tal fato à severidade da fratura e ao uso do método fechado para a redução óssea. Apesar de os animais apresentarem deformidades angulares, não foi notado nenhum efeito sobre a função do membro ou sobre o tempo necessário para a consolidação óssea.

$\mathrm{O}$ uso de antiinflamatórios não-esteroidais ou de opióides deve ser realizado de maneira rotineira tanto no pré como no pós-operatório de procedimentos cirúrgicos em aves (WISSMAN, 1999). A dose de flunixin meglumine recomendada por BENNETT (1992) e JENKINS (1992) varia de 1 a $10 \mathrm{mg} / \mathrm{kg}$, devendo ser administrada uma vez ao dia por três dias consecutivos.

Os objetivos do presente experimento, utilizando pombos domésticos (Columba livia) foram avaliar a eficiência da fixação esquelética externa tipo II, o método fechado de redução das fraturas e o tempo necessário para a consolidação óssea de fraturas diafisárias de tibiotarso.

\section{MATERIAL E MÉTODOS}

Foram utilizados doze pombos domésticos (Columba livia), nove machos, adultos, 
com peso médio de $372,5 \pm 53,85$ gramas, alojados individualmente (machos) ou aos pares (fêmeas) em gaiolas de $1 \mathrm{~m}^{2}$, onde permaneceram por, no mínimo, 15 dias para adaptação ao local e à alimentação ${ }^{\mathrm{a}}$.

Após 12 horas de jejum sólido e líquido, cada ave foi encaminhada ao centro cirúrgico do Laboratório de Cirurgia Experimental do Hospital Veterinário da UFSM, onde foi anestesiada com cloridrato de xilazina ${ }^{\mathrm{b}}$ e cloridrato de cetamina ${ }^{\mathrm{c}}$, na dose inicial de $4 \mathrm{mg} / \mathrm{kg}$ e $20 \mathrm{mg} / \mathrm{kg}$, respectivamente, pela via intramuscular (músculo peitoral). Após o animal estar em plano cirúrgico de anestesia, foi efetuada a remoção manual das penas localizadas na região tibiotársica direita e, em seguida, anti-sepsia do local com gluconato de clorexidina ${ }^{\mathrm{d}} 4 \%$.

Com o paciente em decúbito lateral esquerdo, foi produzida uma fratura na região diafisária do tibiotarso direito utilizando-se pressão digital látero-medial. Após a realização da fratura, quatro pinos de Kirschner (1mm), dois proximais e dois distais ao foco da fratura, foram introduzidos com a ajuda de um introdutor manual de Jacobs, pela face lateral do membro, de maneira a passar pela pele, musculatura, cortical óssea, canal medular, cortical oposta, musculatura e pele. O pino mais proximal e o mais distal foram os primeiros a serem inseridos, seguidos pelos pinos médios. Todos foram introduzidos formando um ângulo de aproximadamente 70 graus em relação ao eixo longitudinal do osso. Após a introdução dos pinos, a fratura foi manualmente reduzida e os pinos foram externamente conectados por duas barras de acrílico autopolimerizávele ${ }^{\mathrm{e}}$, uma na face medial e outra na lateral do tibiotarso (Figura 1A). A distância mantida entre a pele e o acrílico foi de aproximadamente $4 \mathrm{~mm}$.

Após o ato cirúrgico, as aves receberam $2,5 \mathrm{mg} / \mathrm{kg}$ de flunixin meglumine, pela via intramuscular, como terapia analgésica e antiinflamatória, sendo este repetido por mais duas vezes, com intervalo de 24 horas entre cada administração. Foi realizado curativo no local da inserção dos pinos na pele com gaze estéril embebida em nitrofurazona ${ }^{\mathrm{g}}$, e, após, o fixador esquelético externo foi envolvido por uma atadura de crepom. Tal procedimento foi realizado a cada sete dias, até a completa consolidação óssea, quando o aparelho foi removido.

As aves foram encaminhadas ao setor de radiologia, imediatamente após o término da cirurgia, onde foram efetuadas radiografias em incidências ântero-posterior e médio-lateral do membro fraturado (Figura 1B). Após 15 dias do ato cirúrgico, foram realizadas avaliações radiográficas semanais até o completo desaparecimento da linha de fratura, período considerado como o tempo necessário para a consolidação óssea.

$\mathrm{Na}$ avaliação radiográfica, também foram observadas a porcentagem de deslocamento transversal dos fragmentos ósseos, obtida através da divisão do deslocamento transversal dos fragmentos (mm) pelo diâmetro ósseo $(\mathrm{mm})$ multiplicada por 100, a presença de deformidade angular e/ou rotacional e a presença de osteólise no local de inserção dos pinos. Quando da confirmação radiográfica da consolidação óssea, cada ave foi anestesiada com cloridrato de xilazina $(1 \mathrm{mg} / \mathrm{kg})$ e cloridrato de cetamina $(10 \mathrm{mg} / \mathrm{kg})$, ambos pela via intramuscular, para a remoção do aparelho de fixação esquelética externa, efetuada com a ajuda de um alicate ortopédico.

Após 15, 30, 45, 60 e 90 dias do procedimento cirúrgico, foi realizada eutanásia de duas aves, em cada período, utilizando uma dose total de $75 \mathrm{mg}$ de tiopental sódico pela via intracelomática. Para avaliação macroscópica, o tibiotarso foi removido e foi observada a presença ou não de mobilidade óssea no local da realização da fratura. Após o registro fotográfico, o tibiotarso direito foi fixado em formol tamponado a $10 \%$ e, passado um período mínimo de 72 horas, foi descalcificado em solução de ácido nítrico a $10 \%$. Após a descalcificação, foi coletado um fragmento de aproximadamente $2 \mathrm{~cm}$, cujo ponto central era a antiga fratura, que foi processado pela técnica rotineira de inclusão em parafina e coloração pela hematoxilina-eosina, para avaliação microscópica.

\section{RESULTADOS}

O período de adaptação das aves, de 15 dias no mínimo, permitiu que essas pudessem adequar-se à sua nova dieta, ao seu novo ambiente e às pessoas que iriam manipulá-las posteriormente. $\mathrm{O}$ tempo médio e o desvio padrão para a consolidação radiográfica das fraturas (Figura 2) foi de 24,8 \pm 4,89 dias. A porcentagem de deslocamento transversal dos fragmentos ósseos, a presença de deformidade angular e/ou rotacional e o tempo de consolidação da fratura de tibiotarso dos pombos domésticos (Columba livia) encontram-se na tabela 1.

O diâmetro dos pinos utilizados (1mm) para a confecção do fixador esquelético externo tipo II representou 29,43\% do diâmetro do tibiotarso. Na avaliação radiográfica pós-operatória imediata, não foi identificado nenhum caso de fratura ou fissura ocorridos durante a introdução destes pinos.

Não ocorreu drenagem de secreção pelo local da inserção dos pinos em nenhuma ave, além 


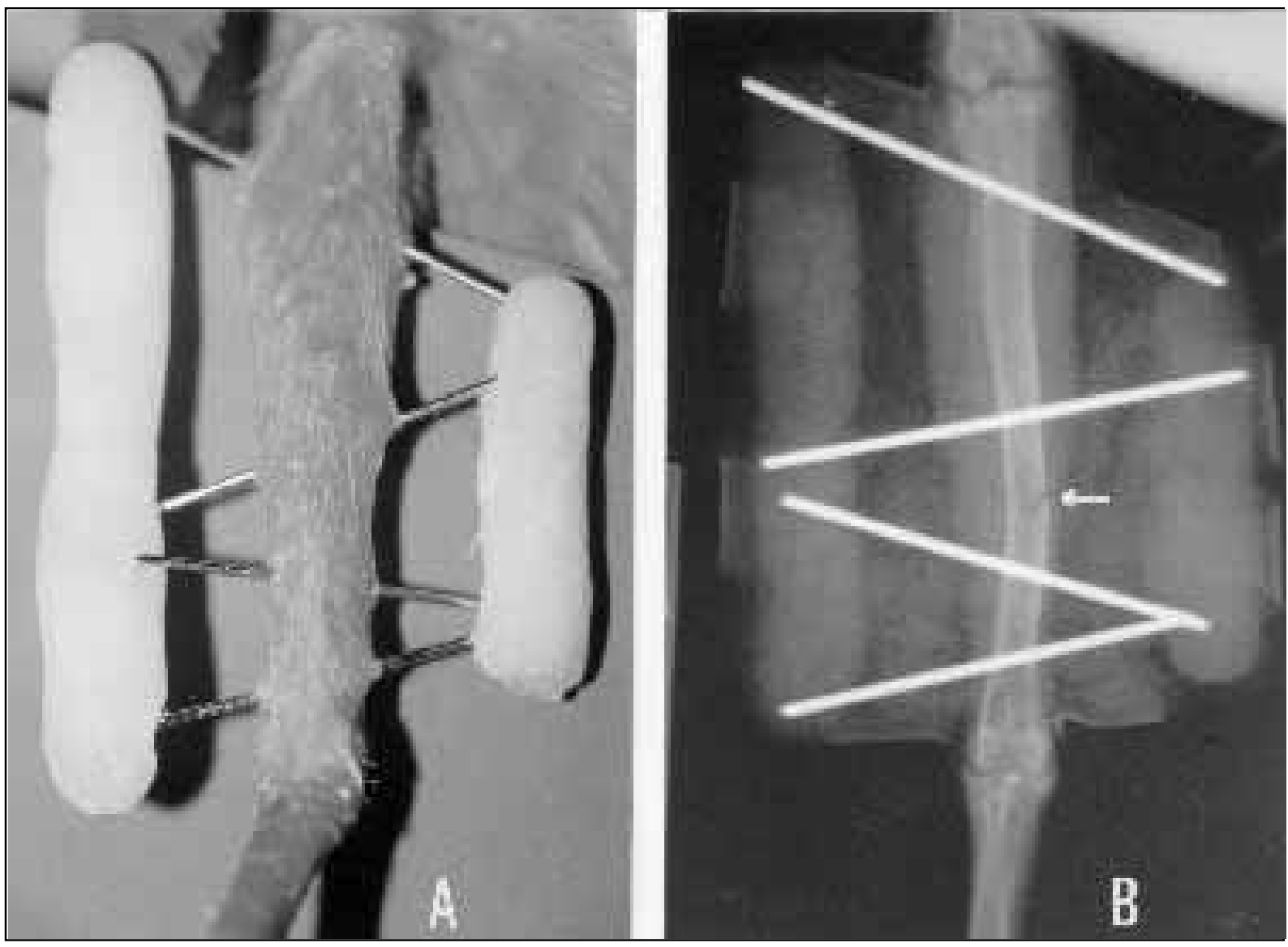

Figura 1 - Redução fechada e fixação esquelética externa tipo II em pombo doméstico (Columba livia). A - Tibiotarso direito após a inserção dos pinos de Kirschner e das barras de acrílico autopolimerizável. B - Aspecto radiográfico de tibiotarso no pós-operatório imediato. Notar a presença da linha de fratura (seta).

de não terem sido observados quaisquer sinais de atrofia muscular, rigidez articular, osteoporose e não-união óssea.

Nas aves submetidas à eutanásia, 15 dias após a colocação do fixador esquelético externo, não foi notada mobilidade no local da fratura, apesar de radiograficamente ainda haver a presença da linha de fratura. Em uma ave, foi observada radiograficamente, aos 29 dias de pós-operatório, a presença de área radiolucente circundando o pino mais proximal, porém não foi observado o afrouxamento do aparelho de fixação esquelética externa.

$\mathrm{Na}$ avaliação histológica, aos 15 dias, foi observado calo ósseo constituído por cartilagem hialina e trabéculas ósseas trançadas, com presença de camada espessa de periósteo. Aos 30 dias, havia menor quantidade de cartilagem hialina e presença de maior quantidade de trabéculas ósseas trançadas. Aos 45, 60 e 90 dias, não foi observada a presença de cartilagem hialina, havendo reabsorção parcial do calo ósseo (remodelamento ósseo).

\section{DISCUSSÃO}

As aves foram alojadas individualmente ou aos pares, pois os pombos, principalmente os machos, costumam disputar violentamente o domínio do ambiente, da alimentação e das fêmeas, o que muitas vezes pode gerar lesões graves e o desencadeamento de estresse, sendo que qualquer um desses problemas poderia afetar drasticamente a confiabilidade dos dados coletados.

Segundo BUSH (1977), WESTFALL \& EGGER (1979) e WILLIAMS et al.(1987), os aparelhos de fixação esquelética externa deveriam ser utilizados apenas em aves de médio e grande porte, pois, caso contrário, poderiam ocorrer fraturas no momento da inserção dos pinos. No presente trabalho, foram utilizadas aves com peso médio de $375 \mathrm{~g}$, e não houve nenhum caso de fratura ou fissura 


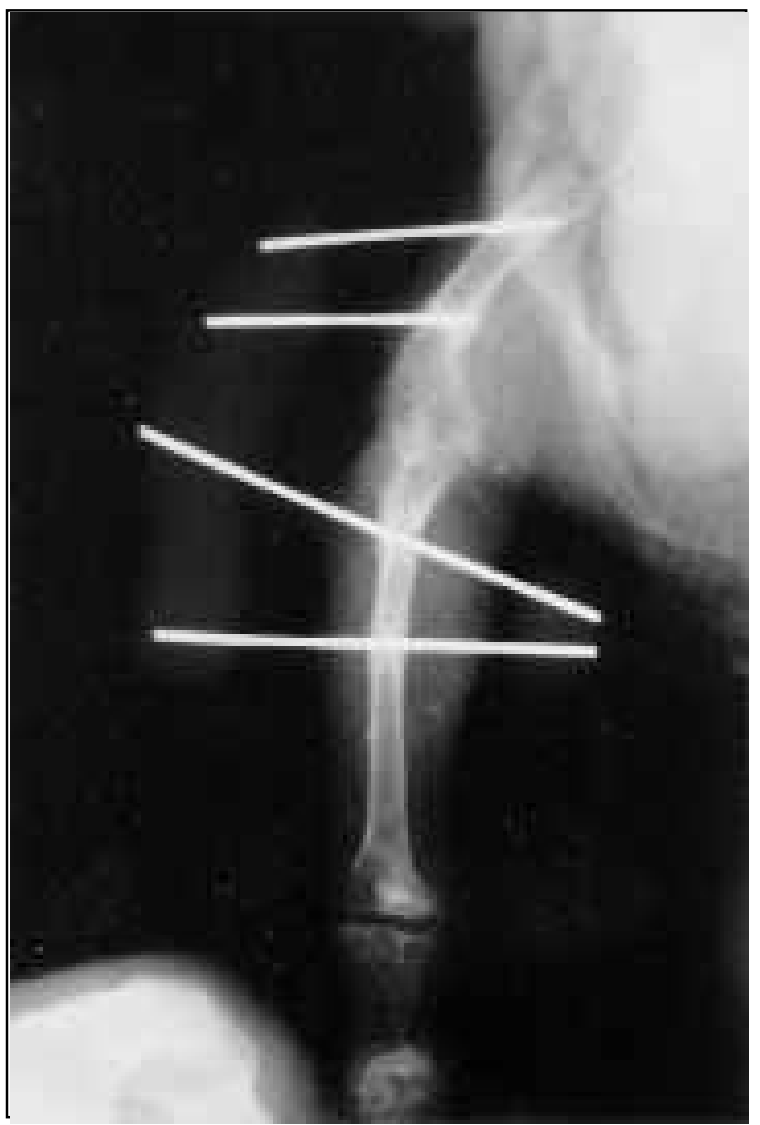

Figura 2 - Redução fechada e fixação esquelética externa tipo II em pombo doméstico (Columba livia). Aspecto radiográfico demonstrando o momento adequado para a remoção do fixador esquelético externo. Note o desaparecimento da linha de fratura (seta).

iatrogênica durante a inserção dos pinos, indicando assim que este método pode ser utilizado em aves com porte similar ao deste experimento sem que ocorram tais complicações.

DEGERNES et al. (1998), em um estudo biomecânico, contra-indicaram o uso de pinos lisos para a confecção de aparelhos de fixação esquelética externa, pois, segundo os autores, esses possuem uma pequena capacidade de fixação ao osso, facilitando assim o afrouxamento ou mesmo a queda do aparelho. Porém, em seu modelo experimental, os pinos foram introduzidos de maneira perpendicular ao osso, o que diminui a interface pino-osso, facilitando, com isso, o afrouxamento do mesmo. No presente trabalho, foram utilizados pinos lisos, porém com angulação de aproximadamente 70 graus em relação ao eixo longitudinal do osso, o que, segundo BRINKER $\boldsymbol{e t}$ al. (1985) e ROE (1995), aumenta a interface pino-osso e assim a capacidade de fixação do pino ao osso, fato esse comprovado pela inexistência de complicações como afrouxamento ou queda do aparelho.
Assim como citado por ROE (1995), o pino de $1 \mathrm{~mm}$ de diâmetro utilizado no presente experimento representou em média $29,43 \%$ do diâmetro ósseo e, ao contrário do citado por TOOMBS (1995) e HARARI et al. (1998), tal relação pino/osso não causou fratura ou fissura radiograficamente visível, mostrando, com isso, que esta pode ser utilizada para a confecção de fixadores esqueléticos externos em pombos.

Assim como relatado por JOHNSON et al. (1989), um grande número de animais apresentou deformidades anatômicas no tibiotarso após a osteossíntese, fato esse justificado pela utilização do método fechado para a redução da fratura. Apesar destas deformidades e como citado por JOHNSON et al. (1989), as aves apresentaram uma utilização normal do membro, o que se justifica pela grande habilidade que possuem para compensar tal problema.

Em um estudo utilizando fixação esquelética externa (tipo II) na tíbia de gatos, RAPHAEL et al. (1994) afirmaram que o aparelho foi bem tolerado, sendo praticamente ignorado pelos animais, permitindo assim a deambulação precoce e prevenindo a atrofia muscular. No presente trabalho, os resultados foram muito similares, apesar de terem sido obtidos de espécie totalmente diferente, o que indica que as aves também se adaptam muito bem ao aparelho de fixação esquelética externa que, portanto, pode ser utilizado nessa espécie sem prejuízos funcionais.

As aves utilizaram adequadamente o membro alguns dias após a osteossíntese, não apresentando nenhum dos sinais citados por BRADEN \& BRINKER (1973), como atrofia muscular, rigidez articular, osteoporose e não-união óssea. Este fato corrobora com os achados de SISK (1983) e PEAD \& CARMICHAEL (1989), os quais afirmaram que os fixadores esqueléticos externos permitem uma movimentação adequada das articulações proximal e distal à fratura quase que imediatamente após a sua colocação, evitando assim as possíveis complicações advindas da não utilização do membro fraturado durante a fase de consolidação óssea.

Assim como citado por BUSH et al. (1976) e NEWTON \& ZEITLIN (1977), a formação do calo teve origem de células progenitoras do periósteo, endósteo e tecidos conectivos, confirmando com isso que não existem diferenças entre a consolidação óssea das aves e dos mamíferos. 
Tabela 1 - Porcentagem de deslocamento transversal dos fragmentos ósseos, presença de deformidade angular e/ou rotacional e tempo de consolidação da fratura de tibiotarso de pombos domésticos (Columba livia) tratados com fixador esquelético externo tipo II.

Alinhamento da fratura

\begin{tabular}{cccccc}
$\begin{array}{l}\text { Número } \\
\text { da ave }\end{array}$ & \multicolumn{2}{c}{ Deformidade } & $\begin{array}{c}\text { Deslocamento transversal dos } \\
\text { fragmentos ósseos }(\%)\end{array}$ & $\begin{array}{l}\text { Tempo de consolidação } \\
\text { da fratura (dias) }\end{array}$ \\
\cline { 2 - 5 } & Angular & Rotacional & Médio-lateral & Ântero-posterior & \\
\hline & & & & 0,00 & 29 \\
P1 & Não & Não & 50,00 & 23,33 & 15 \\
P2 & Não & Não & 0,00 & 22,86 & 22 \\
P3 & Não & Não & 21,05 & 0,00 & 29 \\
P4 & Sim & Não & 12,50 & 25,00 & 29 \\
P5 & Sim & Não & 11,43 & 0,00 & 29 \\
P6 & Sim & Não & 0,00 & 0,00 & 29 \\
P7 & Não & Não & 0,00 & 9,38 & 22 \\
P8 & Não & Não & 11,43 & 19,44 & - \\
P9 & Não & Não & 17,50 & 23,33 & - \\
P10 & Não & Não & 5,71 & 16,67 & 22 \\
P11 & Sim & Não & 20,00 & 0,00 & \\
P12 & Sim & Não & 23,33 &
\end{tabular}

Assim como os resultados obtidos por TUDURY \& RAISER (1985), em cães, WILLIAMS et al. (1987) e WISSMAN (1999), em aves, os sinais radiográficos da consolidação óssea não ocorreram simultaneamente às evidências macroscópicas obtidas durante a necrópsia dos animais com 15 dias de pós-operatório. Tal fato foi devido à rápida formação de calo constituído por cartilagem hialina, que proporciona união e estabilização dos fragmentos, mantendo, porém, a linha de fratura radiograficamente visível.

A dose de flunixin meglumine utilizada nesse experimento ficou de acordo com a recomendada por BENNETT (1992) e JENKINS (1992), e, apesar da dificuldade de se avaliar a sensação dolorosa em aves, os animais mantiveramse alertas e alimentaram-se adequadamente, o que, mesmo subjetivamente, sugere que os animais não sentiam dor. Clinicamente, não houve qualquer complicação com o uso de flunixin meglumine, indicando que este pode ser utilizado para o tratamento da dor pós-operatória em pombos domésticos.

\section{CONCLUSÕES}

O fixador esquelético externo tipo II é eficiente para o tratamento de fraturas diafisárias de tibiotarso em pombos domésticos (Columba livia).

O método fechado de redução de fratura não permite uma redução anatômica dos fragmentos ósseos.

O tempo médio para a consolidação radiográfica de fraturas diafisárias de tibiotarso em pombos domésticos utilizando fixador esquelético externo tipo II é de $24,8 \pm 4,89$ dias.

\section{FONTES DE AQUISIÇÃO}

a - Super esporte 2000 Beppler: Beppler Importação e Exportação Ltda, BR 101, Km 210, São José - SC.

b - Coopazine: Mallinckrodt Veterinária Ltda. Cotia - SP.

- Francotar: Virbac do Brasil. São Paulo $\mathrm{SP}$

d - Gluconato de Clorexidina 4\%: Vico

Farma - Farmácia de Manipulação. Santa Maria - RS.

e - Jet acrílico: Artigos Odontológicos

Clássico. São Paulo - SP.

f - Banamine: Schering-Plough Veterinária.

Jacarepaguá - RJ.

g - Nitrofurazona: IFAL Indústria e

Comércio de produtos farmacêuticos.

Camaquã - RS.

\section{REFERÊNCIAS BIBLIOGRÁ-}

\section{FICAS}

BELLANGEON, M., PATAT, J.L. Osteossíntese das asas dos pássaros. A Hora Veterinária, v.4, n.21, p.13-20, 1984

BENNETT, R.A. Patient preparation for avian surgery. In: ACVS VETERINARY SYMPOSIUM, 1992, Miami, Florida. Proceedings... Miami : The American College of Veterinary Surgeons, 1992. p.622-624.

BRADEN, T.D., BRINKER, W.O. Effect of certain internal fixation devices on functional limb usage in dogs. Journal of the American Veterinary Medical Association, v.162, n.8, p.642-646, 1973.

BRINKER, W.O., VERSTRAETE, M.C., SOUTAS-LITTLE, R.W. Stiffness studies on various configurations and types of external fixators. Journal of the American Animal Hospital Association, v.21, n.6, p.801-808, 1985.

BUSH, M., MONTALI, R.J., NOVAK, G.R., et al. The healing of avian fractures: a histological xeroradiographic study. Journal of the American Animal Hospital Association, v.12, n.6, p.768-773, 1976 .

BUSH, M. External fixation of avian fractures. Journal of the American Animal Hospital Association, v.171, n.9, p.943946, 1977.

DEGERNES, L.A., ROE, S.C., ABRAMS, C.F. Holding power of different pin designs and pin insertion methods in avian cortical bone. Veterinary Surgery, v.27, n.4, p.301-306, 1998.

HARARI, J., SEGUIN, B., PADGETT, S.L. Principles of external skeletal fixation in small animal surgery. Veterinary Medicine, v. 93, n. 5, p. 445-453, 1998.

JENKINS, J.R. Avian soft tissue surgery - part I. In: ACVS VETERINARY SYMPOSIUM, 1992, Miami, Florida. Proceedings... Miami : The American College of Veterinary Surgeons, 1992. p.631-633. 
JOHNSON, A.L., KNELLER, S.K., WEIGEL, R.M. Radial and tibial fracture repair with external skeletal fixation: effects of fracture type, reduction, and complications on healing. Veterinary Surgery, v.18, n.5, p.367-372, 1989.

KUZMA, A. Avian orthopedics: an overview. In: ACVS VETERINARY SYMPOSIUM, 1992, Miami, Florida. Proceedings... Miami : The American College of Veterinary Surgeons, 1992. p.625-627.

MACCOY, D.M. General principles of avian surgery. Compendium on Continuig Education for Practicing Veterinarian, v.13, n.6, p.989-992, 1991.

NEWTON, C.D., ZEITLIN, S. Avian fracture healing. Journal of the American Veterinary Medical Association, v.170, n.6, p.620-625, 1977.

PEAD, M.J., CARMICHAEL, S. Treatment of severely comminuted fracture in a rabbit using a Kirschner-Ehmer apparatus. Journal of Small Animal Practice, v.30, p.579582,1989

RAPHAEL, S.C., RAISER, A.G., PIROLO, J. Tratamento de fratura diafisária tibial, em gatos, com pinos de transfixação percutânea, imobilizados por resina acrílica, com e sem pino intramedular. Arquivos Brasileiros de Medicina Veterinária e Zootecnia, v.46, n.3, p.253-262, 1994.
ROE, S.C. Mechanics of external fixators. In: ACVS VETERINARY SYMPOSIUM, 1995, Chicago, Illinois. Proceedings... Chicago : The American College of Veterinary Surgeons, 1995. p.319-321.

SISK, T.D. External fixation - historic review, advantages, disadvantages, complications, and indications. Clinical Orthopaedics and Related Research, n.180, p.15-22, 1983.

TOOMBS, J.P. A review of the key principles of external skeletal fixation. In: ACVS VETERINARY SYMPOSIUM, 1995, Chicago, Illinois. Proceedings... Chicago : The American College of Veterinary Surgeons, 1995. p.380-381.

TUDURY, E.A., RAISER, A.G. R edução de fraturas distais do fêmur de cães, empregando dois pinos de Steinmann em substituição aos de Rush. Revista do Centro de Ciências Rurais, Santa Maria, v.15, n.2, p.141-155, 1985.

WESTFALL, M.L., EGGER, L.E. The management of long bone fractures in birds. Iowa State Veterinarian, v.41, n.2, p.81-87, 1979.

WILLIAMS, R., HOLLAND, M., MILTON, J.L., et al. A comparative study of treatment methods for long bone fractures. Companion Animal Practice, v.1, n.4, p.48-55, 1987.

WISSMAN, M.A. New tools, diagnostics aid in bone and beak repair in birds. Veterinary Product News, v.11, n.6, p.4445,1999

Ciência Rural, v. 31, n. 6, 2001. 